\title{
Students' perceptions regarding dental courses: An integrative literature review
}

Alexandre F Bulgarelli, Kellyn R Souza, Renato C Roperto ${ }^{1}$

Address for correspondence: Dr. Alexandre Favero Bulgarelli, Fernandes Vieira st, 634 Porto Alegre/RS, Brazil. E-mail: alexandre.bulgarelli@ufrgs.br

\begin{abstract}
Department of Preventive and Social Dentistry, Faculty of Dentistry, Federal University of Rio Grande do Sul, Porto Alegre, Rio Grande do Sul, Brazil, 'Department of Comprehensive Care, Faculty of Dental Medicine, Case Western Reserve University, Cleveland, Ohio, USA
\end{abstract}

\begin{abstract}
Background: Currently, dental courses are concerned with an academic environment with spaces to coach students to construct an ethical and a humane profile. Dental students perceptions regarding their courses need to be the baseline to curricula evaluation. This study aims to comprehend the perceptions regarding dental courses and describe how these perceptions are currently studied.

Materials and Methods: Quantitative and descriptive approach designed by an Integrative Literature Review. Authors constructed the sample of study by means of the descriptors Education; Perception; Dentistry and Curriculum. Authors crossed these descriptors at worldwide databases as Lilacs, PubMed/Medline/WofS, IBECS, Library Cochrane, and SciELO. Results: $76 \%$ of the evidences were developed by means of quantitative studies without application of a validate instrument (68\%). The content, of the 25 articles analyzed, were categorized as: Perceptions about educational and social environment to evaluate an undergraduate curriculum (68\%); Evaluating student's abilities and their academic interests to analyze his/her academic training (24\%); Problem-Based Learning in health undergraduate courses as a possibility for perspective of learning (8\%). The evidence levels of sample selection were III (4\%); IV (52\%); V (28\%) and VI (16\%).

Conclusion: This research considers that new evaluations are necessary in order to validate the information about the students' perception regarding dental course.
\end{abstract}

Key words: Curriculum, dental, dentistry, perceptions, students

\section{Introduction}

Graduate health courses curricula need to be constantly analyzed and evaluated in order to offer dental courses in accordance with current technical innovations of dentistry as well as the demands of community oral health. Under the assumption that it is important to comprehend some students' perceptions, the present study aims to analyze students' perceptions regarding dental courses, embracing the academic environment, and describe the current scientific published literature about this research object. Specifically, it aims to access and synthesize the scientific knowledge involving students' perceptions regarding dental courses, by

\begin{tabular}{|l|l|}
\hline \multicolumn{2}{|c|}{ Access this article online } \\
\hline Quick Response Code: & Website: \\
\hline & www.jeed.in \\
\cline { 1 - 2 } & \\
\hline & \\
\hline
\end{tabular}

means of constructing thematic categories classifying its levels of evidences. ${ }^{[1,2]}$

\section{Materials and Methods}

This study, designed by means of a quantitative method and a descriptive approach, applied the Integrative Literature Review technique. This technique is a scientific method to categorize and classify the evidences to any subject or issue. ${ }^{[3-5]}$ It allows researchers to catch up with the scientific literature. An Integrative Literature Review is a categorization of the literature, which conducts to understand the state of art of any research object. Furthermore, it can be useful to seek methodological concepts, determine future designs of study, and comprehend the state of art of any research object or phenomena. ${ }^{[4-6]}$

The research question described as follows: Which is the scientific literature contribution about students' perceptions regarding dental courses? The development of this research is necessary and important because current review studies published on the last decades are seldom systematically and 
critically designed to evaluate the level of evidence. ${ }^{[3]}$ Indeed, well-designed integrative and systematic review studies are currently necessary to comprehend the issue proposed with this study.

According to these assumptions and based on Gannog, ${ }^{[7]}$ (1997) and Bulgarelli, ${ }^{[8]}$ (2011) this study was designed by the following criteria: (1) Approach to the subject and the problem to be investigated; (2) Sample selection; (3) Construction of the instrument to data collection [Figure 1]; (4) Data collection; (5) Data analysis by means of Content Analysis to categorize and classify the scientific evidence; (6) Presentation of a written report/article discussing the acquired knowledge. The Content Analysis is a scientific method to guide the categorization of the theme based on the content of articles, speeches, or any written documents. ${ }^{[9]}$

The methodological approach of the present study begins with a coherent structure of the research object. ${ }^{[5,10]}$ The research object is the lack of systematic literature reviews to classify scientific evidences about undergraduate students' perceptions



Figure 1: Instrument to data collection to a Integrative Literature Review. Student's perceptions regarding dental courses. Brazil, 2012 regarding medical courses, specially dental courses. Authors reach a sample of 25 scientific articles by means of crossing some descriptors [Figure 2]. The studied sample reflects the authors' criteria to sample selection. The sample selection criteria was: (1) accessed articles at international data base as Lilacs, PubMed/Medline, Índice Bibliográfico Espanhol de Ciências de Saúde/IBECS, Cochrane Library, Scielo and Web of Science; (2) articles accessed by the association between controlled descriptors as Education, Perception, Dentistry and Curriculum; (3) on-line full texts articles; (4) articles published since 1990 .

An initial reading of the studies, herewith the research question culminated in the categorization of the content of each article. The content categories, which are part of instrument, were performed by the content analysis. ${ }^{[9]}$

The instrument contains one variable related to the research level of evidence. The classification of the level of evidence was based on Melnyk and Fineout-Overholt ${ }^{[2]}$ (2005). To data collection, it was applied the instrument which allowed the comprehension, contextualization, and classification of the evidences available at the scientific literature covering the research question. It was performed a descriptive statistic and results were simultaneously presented and discussed.

\section{Results and Discussion}

This study is, at least to author's knowledge, one of the few that explored student's perceptions with an Integrative Literature Review. A total of 25 articles, published from 1990, were read an analyzed [Figure 3]. All full papers, most of them in English (88\%), were from databases as Latin American and Caribean Literature/Lilacs (4\%), PubMed/Web of Science (44\%), and Scientific Electronic Library Online/Scielo (52\%). In the studied sample $(n=25)$, the published studies showed that most of data were collected at the faculty where the studies

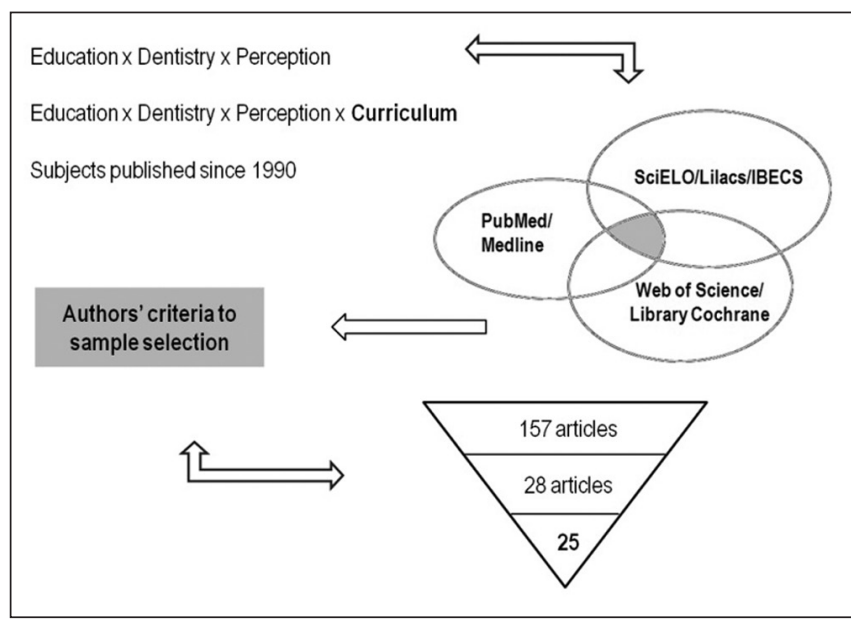

Figure 2: Author's criteria to sample selection. Lilacs, PubMed/ Medline, IBECS, Library Cochrane, SciELO, Web of Science, 2012 
were developed $(68 \%)$ and most of perceptions were from undergraduate students regarding their health courses $(56 \%)$.

Most articles have been published in recent years and in journals with a profile to publish studies about dentistry and education $(40 \%)$. This fact punctuates that paper about students' perceptions regarding dental courses are published at specifics journals. Subjects as dentistry and education are currently being published, probably because the curricula of dental education are adapting themselves to dentists academic training within a humane and ethical perspective oriented to the oral health community necessities. ${ }^{[1]}$

Currently, scientific evidences about dentistry education, students' perceptions regarding dental courses, and different learning processes are important issues to enrich the academic training of dental surgeons. An Integrative Literature Review is a scientific method to evaluate subjects as effectiveness of medical, dental and nursing practices. Moreover, this method can enrich some field of studies as curricula of health courses and pedagogical practices. However, it still not analyzes practices in education. This fact occurs because practices in education are still not evaluated by means of carefully designed and executed trials. ${ }^{\left[{ }^{2}\right]}$ New studies with validated instruments to evaluate students' perceptions and analyze dental curriculum are, currently, necessary. ${ }^{[2]}$

A contemporaneous dental course should promote a wellstructured academic environment to raises future dentists with an ethic and humane profile. One way to deal with this challenge is to comprehend students' perceptions about health courses' environment. Professors, tutors, and researchers can comprehend an academic environment by means of different perspectives. One perspective can be the comprehension of students' perceptions about their own attitudes and behavior during their daily activities at the university. As an example, it is important to comprehend students' perceptions regarding their professional position toward the dress codes to dental activities. Sometimes students have negative attitudes toward some subjects as dress codes, which means that some do not regularly follow the dentistry dress code. ${ }^{\left[{ }^{[]}\right.}$Students need to follow a dress code in order to maintain the hygiene during patient assistance.

The present study showed that $68 \%$ of published researches did not apply validated instrument on controlled trials [Figure 4]. This result suggests a development of new studies focused on practices in health education with validated instruments. Furthermore, $24 \%$ of the studies were qualitative researches and used students' perceptions in order to evaluate the course educational environment. This fact corroborates the necessity to development of well-designed quantitative studies with validated instrument and well-designed qualitative studies to evaluate and analyze the health educational environment. These results suggest a development of ethnographic approach and observational studies with the theoretical support of discourse analysis. Qualitative methods can make a connection between theories and practices to construct knowledge to evaluate undergraduate health course. ${ }^{\left[{ }^{3]}\right.}$

Qualitative methods have some limitations as they provide further information and insights only to a particular group, event, phenomenon, or process. ${ }^{\left[{ }_{13}\right]}$ However, this limitation does not invalidate qualitative studies to guide the comprehension about some phenomena as students' perceptions regarding dental courses. Qualitative data collection can capture depth information, which are not normally gathered using evaluation forms and questionnaires. ${ }^{\left[{ }_{3}\right]}$

This study observed four levels of evidences. Based on Melnyk and Fineout-Overholt ${ }^{\left[{ }^{[}\right]}$the evidence levels observed were: level IV, V, and VI [Figure 5]. This study used this baseline to classify the evidences about student's perceptions because

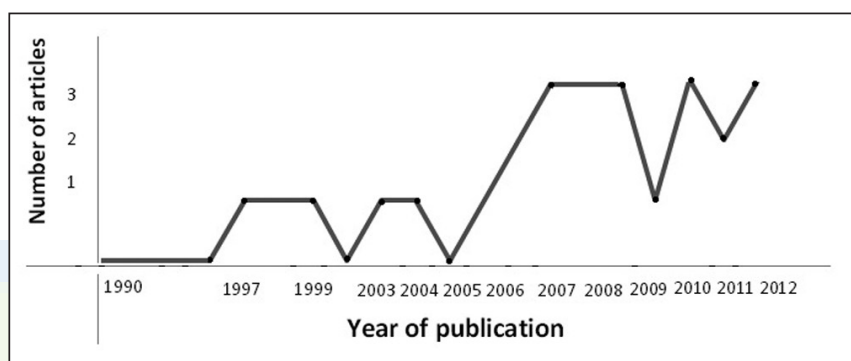

Figure 3: Number of articles published since 1990. Lilacs, PubMed/Medline, IBECS, Library Cochrane, SciELO, Web of Science, 2012

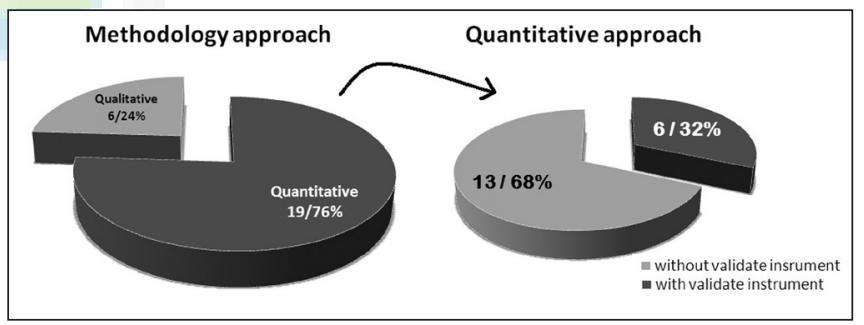

Figure 4: Methodology approaches and use of validate instruments to surveys to study dental courses evaluation. Lilacs, PubMed/Medline, IBECS, Library Cochrane, SciELO, Web of Science, 2012



Figure 5: Level of evidences about students' perceptions regarding dental courses. Brazil, 2012 
there is no specific baseline to classify evidences regarding educational practices on dental courses. The baseline chosen for the present research is the one closest to evaluate the research object. Results shows that students' perceptions regarding dental courses are currently being researched with cohort studies (Level IV), systematic review of qualitative or descriptive studies (level V) and qualitative or descriptive study (VI). ${ }^{[1]}$ This suggests the construction of baselines to classify evidences on practices and researches in dental education.

This paper presents and discusses the main issues of the studied articles according to three categories [Figure 6]. By means of the method of Content Analysis the themes were categorized by clustering similar subjects.

\section{Thematic Category 1. Perceptions regarding} educational and social environment to evaluate an undergraduate curriculum

This category can invite to comprehend a curriculum evaluation observing students' perceptions about their life at the academic environment. Students' perception about their medical courses can be an important instrument to comprehend positive findings to enrich a curriculum of a dental course.

A culture, where a learning environment promotes a good relationship between students and professor, can create a place where students are able to ask questions and learn with possible mistakes. This can construct a good professional. ${ }^{\left[{ }_{3}\right]}$ When a student relates a negative perception of his medical course it is inversely associated to good quality of student life and positive education environment reflecting dissatisfaction with academic life. ${ }^{[4]}$

Now-a-day, dental professors and instructors face the challenge to improve the student's satisfaction by means of enriching the curriculum syllabus and the learning environment to arouse interest for theoretical lessons in the classroom. ${ }^{[9]}$ Toward that, most students prefer classes with teachers who use strong visual presentations, as well as the promotion of taking notes in an easier way. This fact shows the importance of the awareness of teachers about the necessity to make the educational experience more enjoyable. ${ }^{[9]}$

Students' satisfaction about an undergraduate course can be reached with a Problem-Based Learning (PBL). At this process one possible way to evaluate students' satisfaction is to set a series of problem based mapping tasks by using timeslots for workshops instead of summative assessment in order to comprehend what should make dental students satisfied. ${ }^{\left[{ }_{15}\right]}$

Investigations of students' perceptions regarding teaching methods and new learning process technologies are important to reach good quality and results to the teaching process. Literature shows that most students prefer digital techniques



Figure 6: Content of articles studied. Lilacs, PubMed/Medline, IBECS, Library Cochrane, SciELO, Web of Science, 2012

in order to study and learn. ${ }^{[16,17]}$ Students' perceptions can reveal what is important and necessary to a dental course development. Subjects as student stress, fatigue, and absence of professors' feedback and support need to be overcome. ${ }^{[1]}$

Following this rhetorical comprehension, there is a long way to reach the ideal model of evaluating the teaching-learning process. An evaluation of a dental course can include more dialogue between the undergraduate education process and the public health system. This approach reflects a necessity to students spend more time within university practical activities where they can experience the public health system since the beginning of the course. ${ }^{[18]}$ Students' perceptions about these possibilities of dentistry learning was not densely found in the current scientific literature.

Students' perception about the teaching process are significantly important to be evaluated to enhance the teaching process and the student learning improvement. ${ }^{[9]}$ The evaluation of students' perception request instrument with internal consistency as the Dundee Ready Educational Environment Measure/DREEM instrument. ${ }^{\left[{ }^{[7,19]}\right.}$

One challenge to a dentistry professor is to construct a good undergraduate academic training with good orientations, good training environment, and well-designed communication skills. Perceptions of communication barriers between patient and health professional comes through educationrelated barriers as lack of science immersion and the lack of communication training. ${ }^{[20]}$

Dental courses need to be constantly evaluated according to the demands of society and different curricular guidelines in new areas. Geriatric dentistry, health care management and community dentistry corroborate this fact. Professors have an important role on this new global era of teaching dentistry and learning process for training health professionals to be more critical, reflexive, humanistic, and in accordance to society demands. ${ }^{[2]}$

Thematic category 2. Evaluating student's abilities and their academic interests to analyze their educational process

One way to observe the student educational process, during a health course, is to observe the student career interests. Generally, initial career interest is not an accurate predictor of career choice. ${ }^{[2,23]}$ Although, students can become interested during the course while living a collaborative learning process 
with tutors, professors and instructors. ${ }^{[9]}$ This collaborative process can enrich communication aspects to improve social skills and technical ability which are very important to entry employability. ${ }^{[2]}$

The students' interest in a dental course is a reflection of positive appreciation of the atmosphere and the pedagogical teaching methods. Potentially, a satisfactory student life atmosphere can influences students' academic positive selfperception of their environment. This fact will stimulate students to pass more time in campus facing experiences in different situations and activities. ${ }^{[12,25]}$

Despite the fact that this study searched for articles about students' perceptions regarding dental courses, some articles present clinical evaluation of medical students about the performance of laparoscopic cholecystectomies and vascular surgery, ${ }^{[26,2]]}$ and perceptions regarding Veterans Affairs hospitals which provides valuable experience in cardiothoracic training ${ }^{[28]}$ Other article highlight that residents were open to new educational methods such as debates, training with models, workshops and internet-distance-learning. ${ }^{[29,30]}$ This probably occurred because these articles were published with the same combination of descriptors. Somehow, these articles covered all perceptions regarding health courses. This make them part of the statistics in this study.

A curriculum of a dental course needs to be update with the current demographic situation of different populations. For example, a dental course can offer to student the opportunity to work with specialized care for elderly. In this case, it is necessary to evaluated the student level of knowledge in geriatric dentistry. ${ }^{\left[{ }_{3}\right]}$ The elderly and the strategies to assist them must be a priority to dentistry because these strategies promote quality of life. According to literature, students have little experiences during their training in geriatric dentistry, which request a current learning and teaching process to get the student acquainted with dentistry and population aging. ${ }^{[27,31]}$

In summary, a health courses raises for greater contact between student, clinic, professors and instructors. This fact will ensure greater success in training and professional preparation to decision making about careers. ${ }^{[2]}$

\section{Thematic Category 3. Problem-based learning within} health undergraduate courses as a possibility for perspective of learning

The way students construct their knowledge is an issue that stimulates professors to be acquainted with new perspectives on dentistry teaching-and-learning process. PBL can come with an educational process to enrich the structure of dental course syllabus.

The PBL has in its educational process three important aspects. These aspects are: A well-designed research object to stimulate students' interest to know and learn by means of construct a problem solution; creation of tutorials to work together on a problem; and compatible assessment as a presentation of the solution of the problem either orally or by a written report. ${ }^{[3]}$ This perspective of learning can stimulate a positive student perception regarding dental courses.

The students' perceptions are, in some points, related to their prior experiences of learning and what king of material are designed for them to learn. The students' perceptions about a PBL philosophy can promote an approach between and their instructors which is very important to a good academic environment. ${ }^{[3]}$

The PBL can also be used in association with self-studying and traditional conferences and lectures. The student is stimulated and motivated to progress in their training when the association between different ways of learning is applied. However, a traditional conference, popular among residents, have no impact on positive students perceptions at an evaluation of the curriculum of a health course. ${ }^{[33]}$ The PBL is stimulating to the medical undergraduate student and sometimes it does guide the student interests. ${ }^{[34]}$

The PBL philosophy of teaching and learning uses instruments as concept maps to access the students' perceptions of their knowledge. It can be an instrument to create an environment of work in groups. The literature shows that students felt that working in a group with a concept map help them to learn. This perceived benefit outweighs the stress related to completing the concept maps. ${ }^{\left[{ }_{5}\right]}$

In some cases, PBL is still seen with resistance by some dental courses. This happens due to the conservative structure of many colleges and faculties concerning that this methodology can be rejected from part of the students. This results negative students' acting and practicing. ${ }^{[35]}$ However, despite some resistance to curricular changes, the schools and colleges that have joined the PBL have noticed the increase of students' interests in searching for information and resources to construct their knowledge. ${ }^{[35]}$ Toward that, in summary, the PBL aim is the acquisition of more knowledge on certain subject or event, providing moments of larger reflection about the situations lived in the academic environment. This increases the students' trust to develop competences with quality along graduation and to solve problems lived during the academic training.

Final considerations

This study may provide a support for instructors and professors who wish to increase the effectiveness of their teaching-learning process. Furthermore, it can encourage researchers to develop new questionnaires and validate them to provide scientific researches with good levels of evidences about students' perceptions regarding dental courses. This study suggests the construction of new criteria to evaluate scientific evidences. 
This is a study associated to the authors' criteria for sample selection, which developed their interpretation in the context of the evidences reached. This fact may suggest new directions to the development of a specific baseline creating levels of evidences to analyze educational practices in dental undergraduate academic training.

\section{References}

1. Sudhir KM, Mohan GC, Fareed N, Shanthi M. Dental students' perception towards dress code in a private dental institution in Andhra Pradesh: A cross-sectional study. J Ethics Educ Dent 2011;1:68-72.

2. Melnyk BM, Fineout-Overholt E. Making the case for evidence based practice. In Melnyk BM, Fineout-Overholt E, editors. Evidence based practice in nursing and healthcare. A guide to best practice. Philadelphia: Lippincot Williams and Wilkins; 2005. p. 3-24.

3. Davies $\mathrm{P}$. What is evidence-based education? $\mathrm{Br} \mathrm{J}$ Educ Stud 1999;47:108-21.

4. Broome ME. Integrative literature reviews in the development of concepts. In Rodgers BL, Knafl KA. Concept development in nursing: Foundations, techniques and applications. Philadelphia: W.B. Saunders; 2000. p.193-215.

5. Beyea S, Nicoll LH. Writing an integrative review. AORN J 1998;67:877-80.

6. Whittemore R, Knafl K. The integrative review: Updated methodology. J Adv Nurs 2005;52:546-53.

7. Ganong LH. Integrative review of nursing research. Res Nurs Health 1987;10:1-11.

8. Bulgarelli AF, Pinto IC, Mestiner SF, Mestriner Junior W. Communitybased support to elderly care: An integrative review about the scientific publication between 1997 and 2011. RGO — Rev Gaucha Odontol 2011;59:627-32.

9. Bardin L. Content Analysis. $6^{\text {th }}$ ed. Lisbon: Edicoes; 1995. p. 70.

10. Murphy RJ, Gray SA, Straja SR, Bogert MC. Student learning preferences and teaching implications. J Dent Educ 2004;68:859-66.

11. Jorge RR. The curriculum reform and the current state of professional formation in the graduation courses in the Rio de Janeiro State, Brazil. Rev Niterói 2005;12:172-5.

12. Ostapczuk MS, Hugger A, de Bruin J, Ritz-Timme S, Rotthoff T. DREEM on dentists! Students' perceptions of the educational environment in a German dental school as measured by the Dundee Ready Education Environment Measure. Eur J Dent Educ 2012;16:67-77.

13. Victoroff KZ, Hogan S. Students' perceptions of effective learning experiences in dental school: A qualitative study using a critical incident technique. J Dent Educ 2006;70:124-32.

14. Oliveira Filho GR, Sturm EJ, Sartorato AE. Compliance with common program requirements in Brazil: Its effects on resident's perceptions about quality of life and the educational environment. Acad Med 2005;80:98-102.

15. Moni RW, Moni KB. Student perceptions and use of an assessment rubric for a group concept map in physiology. Adv Physiol Educ 2008;32:47-54.

16. Dozic A, Kharbanda AK, Kamell H, Brand HS. European dental students' opinions about visual and digital tooth color determination systems. J Dent 2011;39:23-8.

17. Kossioni AE, Varela R, Ekonomu I, Lyrakos G, Dimoliatis ID. Students' perceptions of the educational environment in a Greek Dental School, as measured by DREEM. Eur J Dent Educ 2012;16:73-8.

18. Chaves IT, Grosseman S. Medical internship and its perspectives:
A case study with educators and students. Rev Bras Educ Méd 2007;31:212-22.

19. Foster Page LA, Kang M, Anderson V, Thomson WM. Appraisal of the Dundee Ready Educational Environment Measure in the New Zealand dental educational environment. Eur J Dent Educ 2012;16:78-85.

20. Dorgan KA, Lang F, Floyd M, Kemp E. International medical graduatepatient communication: A qualitative analysis of perceived barriers. Acad Med 2009;84:1567-75.

21. Lazzarin HC, Nakama L, Cordoni-Júnior L. The role of the teacher according to the perceptions of dentistry students. Saúde Soc 2007;16:90-101.

22. Brandt MG, Wright ED. Medical student career choice and mental rotations ability. Clin Invest Med 2005;28:112-7.

23. Rice CD, Glaros AG, Shouman R, Hlavacek M. Career choice and occupational perception in accelerated option and traditional dental students. J Dent Educ 1999;63:354-8.

24. Maynard ML. Emotional intelligence and perceived employability for internship curriculum. Psychol Rep 2003;93:791-2.

25. Froeschle ML, Gobetti JP, Donahue PM. Faculty attitudes and perceptions about the Institute of Medicine report. J Dent Educ 1999;63:339-45.

26. Hogle NJ, Widmann WD, Ude AO, Hardy MA, Fowler DL. Does training novices to criteria and does rapid acquisition of skills on laparoscopic simulators have predictive validity or are we just playing video games? J Surg Educ 2008;65:431-5.

27. Singh N, Causey W, Brounts L, Clouse WD, Curry T, Andersen C. Vascular surgery knowledge and exposure obtained during medical school and the potential impact on career decisions. J Vasc Surg 2010;51:252-8.

28. Bakaeen FG, Stephens EH, Chu D, Holman WL, Vaporciyan AA, Merrill WH, et al. Perceptions regarding cardiothoracic surgical training at Veterans Affairs hospitals. J Thorac Cardiovasc Surg 2011;141:1107-13.

29. Oxentenko AS, Goel NK, Pardi DS, Vierkant RA, Petersen WO, Kolars JC, et al. Colorectal cancer screening education, prioritization, and self-perceived preparedness among primary care residents: Data from a national survey. J Cancer Educ 2007;22:208-18.

30. Uzuner A, Topsever P, Unluoglu I, Caylan A, Dagdeviren N, Uncu Y, et al. Residents' views about family medicine specialty education in Turkey. BMC Med Educ 2010;10:25-9.

31. Waldrop DP, Fabiano JA, Nochajski TH, Zittel-Palamara KM, Davis EL, Goldberg LJ. More than a set of teeth: Assessing and enhancing dental students' perceptions of older adults. Gerontol Geriatr Educ 2006;27:37-56.

32. Prosser MA. Student learning perspective on teaching and learning, with implications for problem-based learning. Eur J Dent Educ 2004;8:51-8.

33. Itani KM, Miller CC, Church HM, McCollum CH. Impact of a problembased learning conference on surgery residents' in training exam (ABSITE) scores. American Board of Surgery in Training Exam. J Surg Res 1997;70:66-8.

34. Langlois J, Wells GA, Lecourtois M, Bergeron G, Yetisir E, Martin M. Spatial abilities in an elective course of applied anatomy after a problem-based learning curriculum. Anat Sci Educ 2009;2:107-12.

35. Jacob PS. Problem based learning in dental education. J Educ Ethics Dent 2011;1:7-11.

How to cite this article: Bulgarelli AF, Souza KR, Roperto RC. Students' perceptions regarding dental courses: An integrative literature review. $J$ Educ Ethics Dent 2012;2:74-9.

Source of Support: National Council for Scientific and Technological Development/ CNPq., Conflict of Interest: None declared. 